\title{
Evaluation of Nutritional Status by Mid-Upper Arm Circumference Amongst Affluent Children
}

\author{
Maiti S', De D², Ali KM³, Ghosh A4, Ghosh D5, Paul S6 \\ ${ }^{1}$ Soumyajit Maiti, MSc, ${ }^{2}$ Debasis De, MSc, ${ }^{3}$ Kazi Monjur Ali, ${ }^{4}$ Abhinandan Ghosh, MSc. Research Scholars from the Bio-Med \\ Laboratory Science \& Management, Vidyasagar University, Midnapore, India, ${ }^{5}$ Debidas Ghosh, MSc, Ph.D, Professor and \\ Head of Department, ${ }^{6}$ Shyamapada Paul, MSc, PhD, Director. From the Rural Research Institute of Physiology and Applied \\ Nutrition, Midnapore, West Bengal, India.
}

\begin{abstract}
Introduction: Anthropometry is widely accepted as low-cost technique for defining the nutritional status of children. The mid upper arm circumference (MUAC) is a fast screening method in detecting acute malnutrition and it is also a predictor of childhood mortality. Materials and Methods: This is the retrospective study to evaluate the nutritional status based on mid upper arm circumference (MUAC) among urban, pre-school age children. A total of 1060 children, aged 1 to 3 years, attending the vaccination clinic of the Indian Red Cross Society Paschim Medinipur Hospital over a two years period, were enrolled in the study. The measurement of MUAC (in centimetres) was taken by the standard technique. Undernutrition was defined based on age and sex-specific MUAC cut-off values as recommended by the World Health Organization (WHO). Results: Boys were higher level of mean MUAC than girls at all ages and there was no significant sex differences. The age-combined rate of overall undernutrition was $18.96 \%$ and it was slightly higher among the boys (19.38\%) than girls (18.46\%). The age-combined moderate undernutrition was higher among the boys ( $16.08 \%$ vs $14.11 \%)$ but girls' value was higher in case of severe undernutrition (3.28\% vs $4.35 \%)$. Conclusion: The present study showed that a remarkable number of pre-schooler was undernourished based on MUAC.
\end{abstract}

Key words: Nutritional status, MUAC, pre-school Children, Affluent

\section{Introduction}

$\mathrm{N}^{4}$ utritional status of preschool children is of paramount importance, because the foundation for life time health, strength and intellectual vitality is laid during that period ${ }^{1}$. This age group is notoriously fraught with the risk of protein energy malnutrition ${ }^{2}$. Chronic undernutrition in childhood is linked to slower cognitive development and serious health impairments later in life that reduce the quality of life of individuals ${ }^{3}$. As well as it continues to be a primary cause of ill-health and premature mortality among children in developing countries ${ }^{4}$. The legacy of malnutrition, especially among preschool children is a major public health problem and a huge obstacle to overall national development ${ }^{5}$. Their nutritional status is a sensitive indicator of community health and nutrition ${ }^{3}$. In India, infants and preschool children (15\% of the total population) are the vulnerable

Manuscript received: $18^{\text {th }}$ December 2011

Reviewed: $16^{\text {th }}$ February 2012

Author Corrected: $7^{\text {th }}$ April 2012

Accepted for Publication: $30^{\text {th }}$ April 2012 segments and suffer highest rates (40\%) of mortality and morbidity ${ }^{2}$. On the contrary, due to nutritional transition in urban area this situation also results decreased prevalence of malnutrition in childhood ${ }^{6}$.

Anthropometry is widely acceptable as low-cost technique for defining the nutritional status of children? ${ }^{7}$. Consistent and precise anthropometric assessment of growing children thus facilitates early identification and timely interventions for emerging health problems. The MUAC is a fast screening method in detecting acute global malnutrition and a good predicting indicator of risk of imminent death. It is also a predictor of childhood mortality ${ }^{8}$. The MUAC is a relatively simple measurement/index, but with a fixed cut off, it ignores age related changes. Compared with weight-for height, MUAC has a sensitivity of $24.6 \%$ and a specificity of $94.8 \%{ }^{9}$ and appears to be a better predictor of childhood mortality than weight-for height. There are several practical and theoretical advantages of using MUAC rather than weight-for-height for the determination of nutritional status ${ }^{4}$. Moreover, in community based 
studies, mid-upper arm circumference (MUAC) appears to be a superior predictor of childhood undernutrition than many other anthropometric indicators ${ }^{7}$.

Given the relevance of undernutrition in preschool children and scanty information on MUAC based study in West Bengal ${ }^{3,4,10,11}$, we endeavoured to evaluate nutritional status of children aged 1-3 years from affluent societies using the WHO age and sex specific MUAC cutoff points.

\section{Materials and Methods}

\section{subjects and methods}

This is the retrospective study for the assessment of nutritional status of affluent pre-school children (1 to 3 years aged) using hospital records for the period of January 2010 to December 2011. Information on age, sex, mid upper arm circumference and family income was noted from hospital registers. The socio-economic status of the subjects was screened based on the social classification as described by recent Indian study ${ }^{12}$. Only high income status (social class II) children from Midnapore Town of West Bengal were included in the present study. Total 1060 pre-school children, 578 boys and 482 girls attending routine child health care vaccination clinic of Indian Red Cross Society Paschim Medinipur district branch hospital were assessed. The minimum estimated sample size $(n=773)$ was calculated using the standard formula $\left.\left[n=z^{2} p q\right) / d^{2}\right]^{13}$, based on a prevalence $(p=77.8)$ of undernutrion using MUAC $^{9}$ with $3 \%$ precision (d) at $95 \%$ confidence interval, where, $\mathrm{q}=\mathrm{p}-1$ and $\mathrm{z}=1.96$.

\section{Assessment of nutritional status}

The mid upper arm circumference (MUAC) was measured (in centimetres) on each subject following the standard techniques ${ }^{14}$.
Nutritional status of the children was evaluated using the following scheme?

- Moderate undernutrition: <-2 standard deviation (SD) Z-score value.

- $\quad$ Severe undernutrition: <-3 SD Z-score value Where SD refers to the age and sex-specific WHO standard deviations Z-score value of MUAC.

- Between sexes differences in means of MUAC was tested by Student's t-test. Age group variation in MUAC was tested by One Way ANOVA test. Statistical significance was set at $p<0.05$.

\section{Results}

The age and sex specific mean (SD) of MUAC are presented in table 1 . The mean $( \pm S D)$ MUAC of boys and girls were $14.71 \pm 1.17$ and $14.68 \pm 1.0$, respectively. Results revealed that mean MUAC was increasing with advancement of age and boys were higher value than girls at all ages. Significant sex differences were not showed at any ages.

The prevalence of undernutrition among the preschool children is presented in table 2. The age combined rates of overall (moderate and severe) undernutrition was $18.96 \%$, where boys (19.38\%) was slightly higher than in girls (18.46\%). The age combined frequency of moderate undernutrition was higher in boys than in girls (16.08\% vs 14.11). But when we consider the severe undernutrition it was opposite manner (3.28 vs 4.35). In case of boys, there was decreasing trend in the rates of overall undernutrition from 1 to 3 years.

Table 1: Mean and standard deviation of MUAC of the preschool children by age and sex

\begin{tabular}{|c|c|c|c|c|c|c|}
\hline \multirow{2}{*}{$\begin{array}{c}\text { Age group (in } \\
\text { year) }\end{array}$} & \multicolumn{2}{|c|}{ Boys } & \multicolumn{2}{|c|}{ Girls } & \multicolumn{2}{c|}{} \\
\cline { 2 - 7 } & No. & Mean (SD) & No. & Mean (SD) & $\boldsymbol{t}$-value & $\boldsymbol{p}$-value \\
\hline 1 & 146 & $14.61(0.96)$ & 122 & $14.54(0.81)$ & -0.62 & 0.51 \\
\hline 2 & 237 & $14.72(1.40)$ & 206 & $14.71(1.08)$ & -0.06 & 0.95 \\
\hline 3 & 195 & $14.79(0.97)$ & 154 & $14.75(1.01)$ & -0.36 & 0.71 \\
\hline
\end{tabular}

Table 2: Nutritional status of affluent pre-school children based on MUAC

\begin{tabular}{|c|c|c|c|c|c|c|c|c|c|}
\hline \multirow{2}{*}{$\begin{array}{l}\text { Age group } \\
\text { (in year) }\end{array}$} & \multicolumn{4}{|c|}{ Boys Undernutrition } & \multicolumn{4}{|c|}{ Girls Undernutrition } & \multirow{2}{*}{$\begin{array}{c}\text { Sex } \\
\text { combined }\end{array}$} \\
\hline & No & Severe & Moderate & Overall & No & Severe & Moderate & Overall & \\
\hline 1 & 146 & $5(3$ & 8) & 31( & 122 & & $19(15.75)$ & $22(1$ & $53(19.77)$ \\
\hline 2 & 237 & $7(2.95)$ & $40(16.87)$ & $47(19.83)$ & 206 & $11(5.34)$ & 17.47) & 47 & $94(21.21)$ \\
\hline 3 & 195 & $6(3.07)$ & $28(14.36)$ & $.43)$ & 154 & $7(4.54)$ & $13(8.44)$ & $20(12.99)$ & $54(15.47)$ \\
\hline Total & 578 & $19(3.28)$ & $93(16.08)$ & $112(19.38)$ & 482 & $21(4.35)$ & $68(14.11)$ & $89(18.46)$ & 201(18.96) \\
\hline
\end{tabular}




\section{Discussion}

Malnutrition poses a grave risk to the health of preschool children in developing countries. Being the most vulnerable segment of the population, the preschool children are at greatest risk of malnutrition'. Therefore, measurement of MUAC is a quick and reliable method for screening children to identify those who are seriously malnourished ${ }^{4}$. Several researchers worldwide have used MUAC to identify children as having moderate and severe acute malnutrition for its simplicity $3,4,8,10,11$.

The overall prevalence of undernutrition was $18.96 \%$, these rates was slightly higher among boys than girls. The prevalence of undernutrition among the preschool age children of the present study was much lower than those reported MUAC based study among poor preschool children of North 24 Parganas $(77.8 \%)^{10}$ and Hooghly district $(64.5 \%)^{3}$ of West Bengal. The rate of undernutrition among the rural Bengalee children of 3-5 years old (by using MUAC) was $35.11 \% 4$. A study conducted in immunization clinic of Kolkata ${ }^{11}$, showed that the rate of undernutrition (28.6\%) were comparatively higher than our data. Where Chiabi et $a l^{8}$, observed that $21.6 \%$ Ugandan preschooler were suffering from malnutrition on the basis of mid arm circumference. However, our data showed low prevalence of undernutrition than other MUAC based study. This might be due to the present study subjects were from affluent societies. Possibly high income families can access proper nutrition. Low prevalence of malnutrition of these study participants indicates better living conditions, particularly with regards to access to food and health care ${ }^{6}$. Along with this, the study also showed that a remarkable number of pre-schooler was undernourished. In our country still considerable population of pre-school children suffers from different grades of malnutrition. The present study indicates that at this stage epidemiological and nutritional transition among the affluent children in the urban area in our country. It must be mentioned here that one of the limitations of this study was the lack of information on detailed dietary history of the subjects.

\section{Conclusion}

In conclusion, present study indicated that a remarkable number of pre-school children were undernourished based on MUAC and MUAC seems to be a potential anthropometric indicator for the assessment of child nutrition.

Acknowledgements: We acknowledge with deep gratitude the cooperation and endurance of the Indian Red Cross Society Paschim Medinipur district branch. All subjects included in the study are gratefully acknowledged.

\section{Funding: None \\ Conflict of Interest: None \\ Permission from IRB: Not Required}

\section{References}

1. Verma R, Prinja S. Assessment of nutritional status and dietary intake of pre-school children in an urban pocket. Internet J Epidemiol 2008;6:1.

2. Gupta VM, Shukla KK. Epidemiological correlates of protein energy malnutrition in pre-school children. Ind J Prev Soc Med 1992;23:26-32.

3. Mandal G, Bose K. Assessment of undernutrition by mid-upper arm circumference among pre-school children of Arambag, Hooghly District, West Bengal, India: An observational study. Internet J Pediatr Neonatol 2009;11:1.

4. Biswas S, Bose K, Mukhopadhyay A, Bhadra M. Midupper arm circumference based undernutrition among Bengalee children of Chapra, West Bengal, India. Iran J Pediatr 2010;20(1):63-68.

5. Bishno P, Sehgal K, Kwatra A. Anthropometric measurements of preschool children as effected by socioeconomic factors. Asia Pac J Clin Nutr 2004;13(Suppl.):S132.

6. Shoeps DO et al. Nutritional status of preschool children from low income families. Nutr J 2011;10:43.

7. WHO. Physical Status: the use and interpretation of anthropometry: Technical report series Geneva; World Health Organization; 1995. Report No.:854.

8. Chiabi A, Tchokoteu PF, Takou V, Fru F, Tchouine F. Anthropometric measurements of children attending a vaccination clinic in Yaounde, Cameroon. African Health Sciences 2008;8(3):17479.

9. Joseph B, Rebello A, Kullu P, et al. Prevalence of malnutrition in rural Karnataka, South India: a comparison of anthropometric indicators. $J$ Health Popul Nutr 2002;20(3):239-44.

10. Bisai S. Nutrition status based on mid upper arm circumference among urban, poor pre-school children in North 24 Parganas, West Bengal, India. Ser J Exp Clin Res 2010;11(4):141-45.

11. Chatterjee S, Saha S. A study on knowledge and practice of mothers regarding infant feeding and nutritional status of under-five children attending immunization clinic of a medical college. Internet $J$ Nutr Wellness 2008; 5:1. 
12. Agarwal AK. Social Classification: The need to update in the present scenario. Indian J Comm Med 2008; 33(1):50-51.

13. Cochran WC. Sampling techniques. New York: Wiley. 1963.
14. Lohman TG, Roche AF, Martorell R. Anthropometric Standardization Reference Manual. Chicago; Human Kinetics Books 1988.

\section{How to cite this article?}

Maiti S, De D, Ali KM, Ghosh A, Ghosh D, Paul S. Evaluation of Nutritional Status by Mid-Upper Arm Circumference Amongst Affluent Children. J Nepal Paediatr Soc 2012;32(2):113-116. 